\title{
Integrasi Pengembangan Techno Park dan Mitigasi Bencana Daerah Volcano Hosted Geothermal Cangar, Arjuno-Welirang Berbasis Metode Seismik
}

\begin{tabular}{l}
\hline Received \\
15 Februari 2018 \\
Revised \\
28 April 2018 \\
Accepted for Publication \\
20 Mei 2018 \\
Published \\
22 Mei 2018 \\
\hline
\end{tabular}

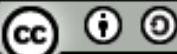

This work is licensed This work is licens under a Creative ShareAlike 4.0 International License.

\author{
S Maryanto ${ }^{1,2^{*}}$ \\ 1. Jurusan Fisika, Fakultas MIPA, Universitas Brawijaya, J1. Veteran, Malang, 65145, Indonesia \\ 2. Pusat Energi dan Sumber Daya Alam, Lembaga Penelitian dan Pengabdian Masyarakat, Universitas \\ Brawijaya, Jl. Veteran, Malang, 65145, Indonesia \\ *E-mail: sukir@ub.ac.id
}

\begin{abstract}
The integration concept of Technopark development and hazard mitigation has been carried out in Volcano Hosted Geothermal area using Seismic method. The goal of this research was to identified the distribution of microearthquake epicenter and hypocenter and Peak Ground Acceleration (PGA) value which were determined by using particle motion analysis and Kanai method. Data acquisition was conducted at Techno Park development site and Volcano-Geothermal Observatorium Cangar using seismograph TDL-303S and also homemade seismometer based on MEMS. The result of this research, We got the microearthquake epicenter distribution around Cangar hotsprings (hypocenter 4-140 meters) and around Welirang crater (hypocenter 985-2152 meters) associated with faults. PGA value in Cangar ranged from 11.23 gal to 21.8 gal. The range of those values indicated the level of risk due to tectonic earthquakes in the research area categorizes as a safe area, so it can be used to monitoring Arjuno-Welirang activities.
\end{abstract}

Keywords: Techno Park, Volcano Hosted Geothermal, Hazard Mitigation, Seismic

\begin{abstract}
Abstrak
Telah dilakukan integrasi konsep pengembangan Techno Park dan Mitigasi Bencana pada kawasan Volcano Hosted Geothermal menggunakan metode seismik. Tujuannya untuk mengetahui sebaran episenter dan hiposenter gempa bumi mikro dan sebaran nilai Peak Ground Acceleration (PGA) yang ditentukan menggunakan analisis pergerakan partikel dan metode Kanai. Akuisisi data dilakukan di lokasi pengembangan Techno Park dan observatorium Gunungapi dan Geothermal Cangar menggunakan seismograf TDL-303S dan juga dikembangkan homemade seismometer berbasis MEMS. Dari penelitian yang telah dilakukan, didapatkan sebaran episenter gempa mikro di sekitar titik mata air panas Cangar (kedalaman 4-140 meter) dan di sekitar kawah gunung Welirang (kedalaman 985-2152 meter) yang berasosiasi dengan patahan. Nilai PGA di Cangar berkisar 11.23 gal hingga 21.8 gal. Rentang nilai tersebut menunjukkan tingkat risiko akibat gempa tektonik pada daerah penelitian termasuk kategori aman, sehingga layak untuk pengembangan daerah monitoring erupsi gunungapi Arjuno Welirang.
\end{abstract}

Kata Kunci: Techno Park, Volcano Hosted Geothermal, Mitigasi Bencana, Seismik.

\section{Pendahuluan}

Saat ini Universitas Brawijaya sedang mengembangkan lokasi pembangunan Agrotechno Park II [1] di daerah Cangar, kota Batu, Jawa Timur (Gambar 1). Salah satu pembangunan yang rencananya akan dikembangkan di daerah ini adalah pusat penelitian geothermal yang berasosiasi dengan gunung api Arjuno-Welirang. Gunung Arjuno-Welirang merupakan salah satu gunung api yang memiliki potensi geothermal yang sumbernya berasal dari bawah kawah gunung Welirang berasosiasi dengan batuan andesit [2]. Daerah Cangar merupakan salah satu titik lokasi sumber potensi panas bumi yang ada di sekitar Arjuno-Welirang, yang ditunjukkan dengan adanya mata air panas dan fumarola. Mata air 
panas di kompleks Arjuno-Welirang tersebar di Padusan, Coban dan Cangar, sementara fumarola muncul di puncak kompleks gunung Arjuno-Welirang [3]. Besarnya energi geothermal di kompleks Arjuno Welirang kira-kira sekitar 280 Mwe $[3,4]$. Sistem geothermal di Arjuno-Welirang diketahui merupakan sistem hidrothermal [5-13]. Mata air panas di daerah ini muncul akibat aktivitas hidrothermal tersebut. Air dalam tanah yang mengalami kontak langsung dengan suatu sumber panas akan memiliki temperatur tinggi dan bergerak ke atas. Sedangkan air yang lebih dingin akan bergerak turun ke bawah. Aktivitas ini disebut sebagai suatu siklus arus konveksi dalam sistem hidrothermal [6]. Akibat dari aktivitas ini akan menimbulkan rekahan bawah permukaan karena gerakan air panas yang berusaha mencari area yang memiliki tekanan lebih rendah daripada sekitarnya. Akibat dari pergerakan air panas di dalam rekahan inilah yang menyebabkan munculnya gempa bumi dalam skala mikro.

Selain mengidentifikasi potensi geothermal yang ada di sekitar lokasi pembangunan Agrotechno Park Cangar, gempa bumi yang terjadi di sekitar wilayah gunung api juga patut diwaspadai karena akan memengaruhi kondisi bangunan yang ada di area tersebut saat terjadi gempa. Kegempaan yang terjadi di sekitar area lokasi pembangunan biasanya berasal dari aktivitas tektonik maupun aktivitas vulkanik dari bawah gunung api Arjuno-Welirang. Sebagai langkah awal mitigasi dalam pembangunan Agrotechno Park Cangar Universitas Brawijaya dan juga mengidentifikasi gempa mikro yang diakibatkan oleh aktivitas hidrothermal di sekitar area tersebut, penelitian ini dilakukan dengan melakukan analisis pergerakan partikel dan analisis Peak Ground Acceleration (PGA).

Sedangkan analisis nilai PGA dilakukan untuk menggambarkan tingkat resiko atau kerusakan akibat gempa bumi. Tingkat resiko ini berbeda-beda di tiap lokasi bergantung dengan kondisi geologi di sekitar area tersebut $[14,15]$.

Penelitian yang terpadu dan lintas disiplin ilmu untuk dapat memahami tingkah laku gunung api masa kini dan masa lampau, kemudian memantau aktivitas yang sedang berlangsung, dan secara bijak mengelola manfaat dari keberadaan gunung api untuk berbagai aspek kehidupan adalah kunci untuk hidup harmonis dengan gunung api.

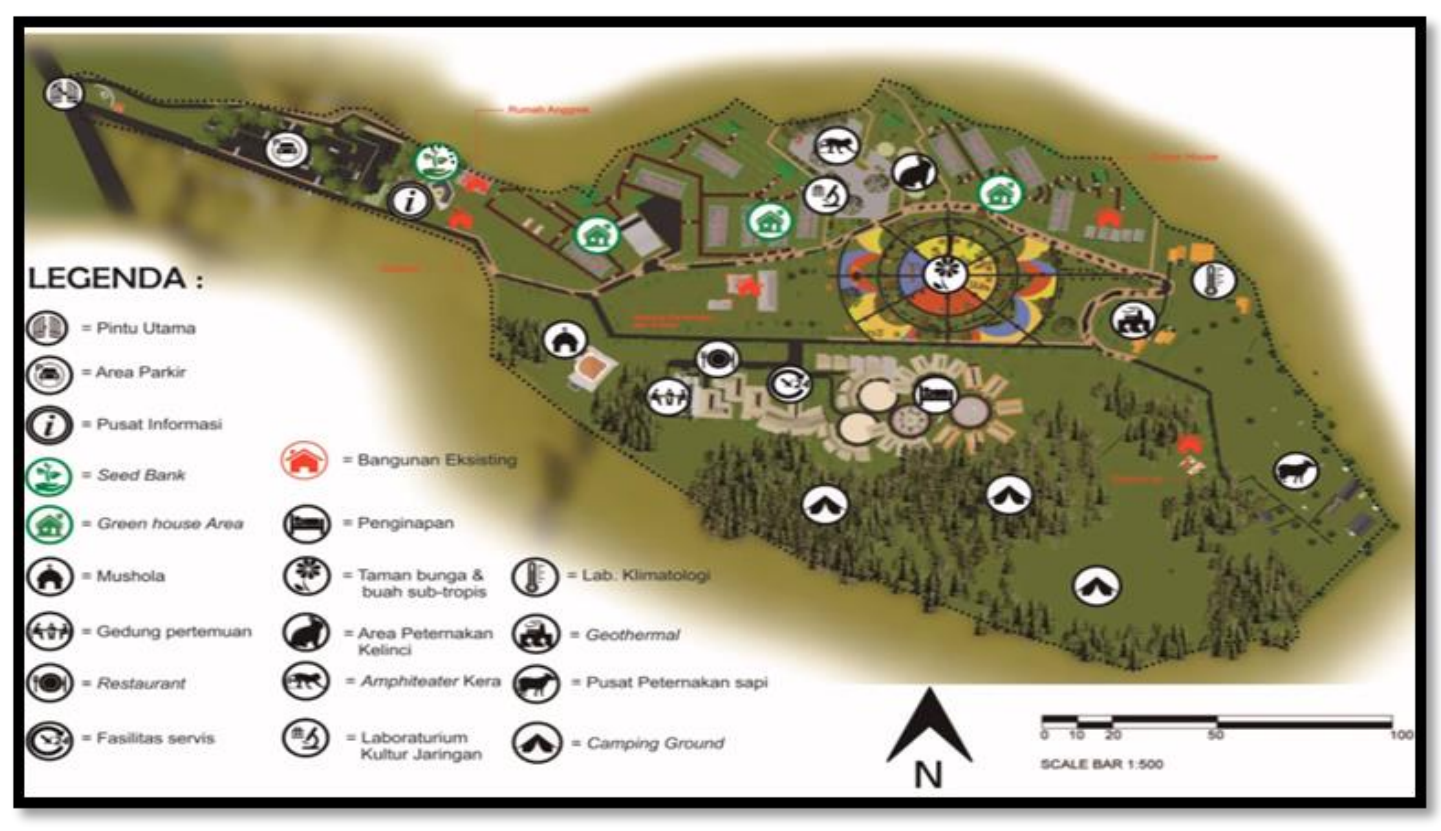

Gambar 1. Desain Agrotechno Park Universitas Brawijaya di Cangar [1] 


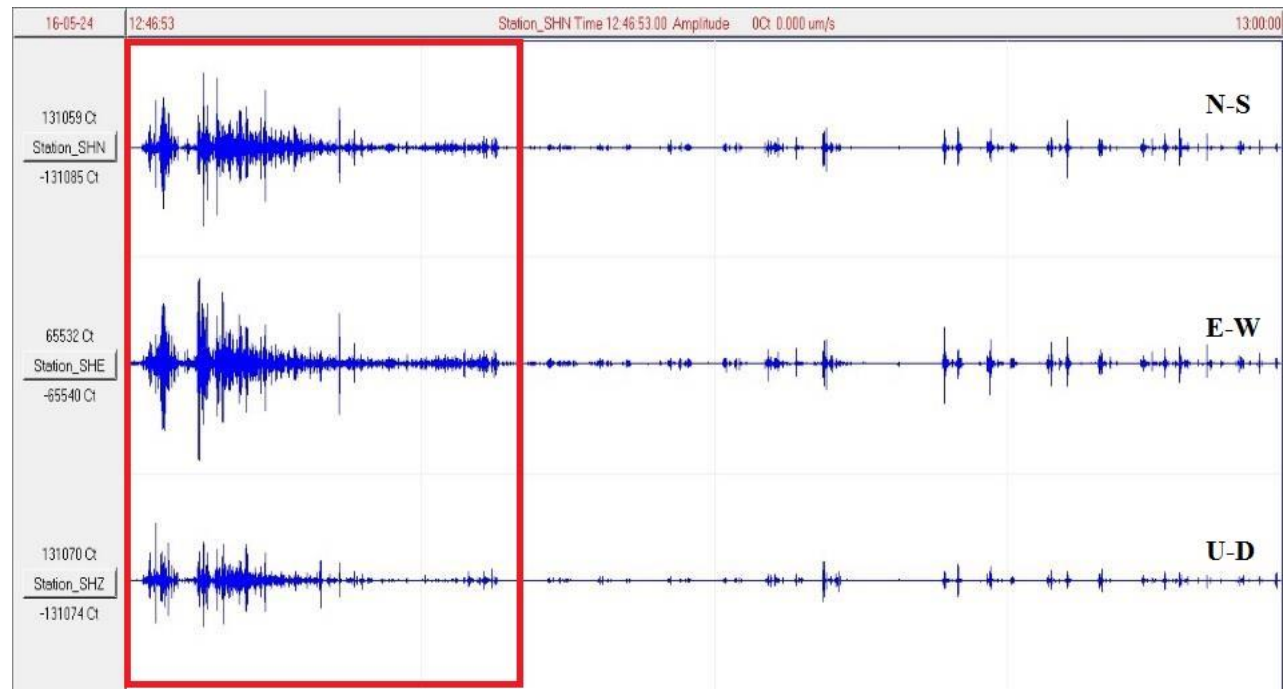

Gambar 2. Contoh sinyal noise pada perekaman gempa mikro di Cangar.

Tabel 1. Hubungan nilai PGA dengan skala MMI (BMKG)

\begin{tabular}{ccc}
\hline Deskripsi Sederhana & PGA (gal) & Skala MMI \\
\hline Tidak dirasakan & $<2.9$ & I - II \\
Dirasakan & $2.9-88$ & III - V \\
Kerusakan ringan & $89-167$ & VI \\
Kerusakan sedang & $168-564$ & VII - VIII \\
Kerusakan berat & $>564$ & IX - XII \\
\hline
\end{tabular}

\section{Metode Penelitian}

Penelitian ini dilakukan di daerah Cangar, kota Batu Kabupaten Malang, Kabupaten Pasuruan. Data penelitian diambil dengan menggunakan TDL-303S dan juga homemade seismometer berbasis MEMS. Perekaman data dilakukan selama 30 menit hingga 3 jam dengan sampling interval sebesar $100 \mathrm{~Hz}$ atau 0.01 sekon. Data hasil perekaman selanjutnya diseleksi dengan menghilangkan noise yang muncul di rekaman data akibat aktivitas lain selain kejadian gempa mikro, misalnya aktivitas manusia atau aktivitas alam seperti suara angin atau suara kendaraan yang melaju di sekitar area perekaman. Gambar 2 merupakan contoh data perekaman di Cangar selama 13 menit 7 sekon. Bentuk sinyal seismik yang terekam (dalam kotak merah) merupakan salah satu noise yang disebabkan oleh aktivitas manusia.

Penentuan episenter dan hiposenter dilakukan dengan analisis pergerakan partikel. Analisis tersebut diterapkan untuk stasiun perekaman yang mampu mencatat 3 komponen, yaitu dua komponen horizontal (N-S, E-W) dan satu komponen vertical (U-D). Amplitudo gelombang dari setiap komponen merupakan parameter yang diukur untuk menentukan arah dan kedalaman sumber gempa. Ploting amplitude dalam komponen horizontal digunakan untuk penentuan episenter, sedangkan hiposenter ditentukan sudut azimutnya menggunakan ploting antara komponen horizontal dan komponen vertikal [16].

Untuk penentuan nilai PGA dilakukan dengan menggunakan metode Kanai [17-19]. Menurut Kanai dan Tanaka (1961), nilai PGA biasanya dipengaruhi oleh kondisi geologi yang ada di sekitar lokasi gempa [20]. Hasil dari nilai PGA ini kemudian akan dikonversi menjadi nilai intensitas gempa bumi sesuai skala dari BMKG 2016 seperti yang ditunjukkan pada Tabel 1.

\section{Hasil dan Pembahasan}

Dari hasil analisis pergerakan partikel, sebaran episenter gempa mikro banyak terdapat di sekitar mata air panas Cangar I dan II dengan kedalaman hiposenter yang cukup dangkal yaitu 4-140 meter dari 
permukaan (Gambar 3a). Kejadian gempa mikro yang muncul di sekitar lokasi mata air panas diduga diakibatkan oleh adanya aliran fluida yang panas dan memiliki tekanan tinggi sehingga aliran fluida ini bergerak naik menuju permukaan. Kontak antara dorongan fluida bertekanan dengan batuan di atasnya diduga menimbulkan retakan-retakan yang akhirnya terekam sebagai gempa mikro. Adanya patahan di sekitar mata air panas juga dapat dikatakan aktivitas hidrothermal di area ini saling memiliki korelasi. Berdasarkan penelitian terdahulu menggunakan metode geolistrik di bawah permukaan Cangar banyak terdapat patahan minor sehingga memungkinkan kejadian gempa yang tidak berdekatan dengan patahan [21].

Kejadian gempa mikro juga muncul di sekitar Kawah gunung Welirang dengan kedalaman 9852152 meter di bawah kawah (Gambar 3b). Untuk kejadian di area ini diduga muncul akibat aktivitas magma gunung Welirang. Sebaran aktivitas ini diduga berasal di sepanjang dinding saluran pipa konduit kawah gunung Welirang. Pada Gambar 3, terdapat aktivitas yang dihubungkan oleh garis putus berwarna merah. Berdasarkan peta geologi gunung Arjuno-Welirang, di sepanjang kerucut kawah gunung Arjuno-Welirang terdapat patahan. Sehingga kejadian gempa mikro di area tersebut diduga berasal dari rekahan bawah permukaan yang berkorelasi dengan patahan dangkal tersebut.

Nilai PGA dalam penelitian ini diperoleh dari perhitungan persamaan Kanai yang dipengaruhi oleh periode dominan tanah dan beberapa parameter gempa bumi (magnitude dan hiposenter). Informasi yang gempa bumi yang digunakan dalam penelitian ini adalah gempa bumi Malang tanggal 16 November 2016 dengan magnitude 6.2 skala Richter. Nilai PGA di daerah Cangar memiliki rentang rentang nilai 15.02 gal hingga 21.8 gal. Gambar 4 menampilkan peta kontur sebaran nilai PGA di sekitar area pembangunan Agro Techno Park Cangar yang di-overlay dengan peta daerah serta lokasi titik perekaman. Dari Gambar 4 diketahui bahwa nilai PGA rendah tersebar di arah Barat area penelitian dengan rentang nilai 11-15 gal, ditunjukkan dengan kontur berwarna cenderung biru. Nilai PGA tinggi ditunjukkan oleh warna kontur yang cenderung memerah di tengah-tengah area penelitian dengan rentang nilai 18-21 gal. Berdasarkan kondisi lapangan, lokasi tersebut telah dibangun sebuah lahan perkebunan. Selain itu kondisi topografi lokasi tersebut berupa tanjakan (dataran miring). Kondisi topografi tersebutakan memengaruhi kestabilan tanah akibat goncangan gempa bumi.
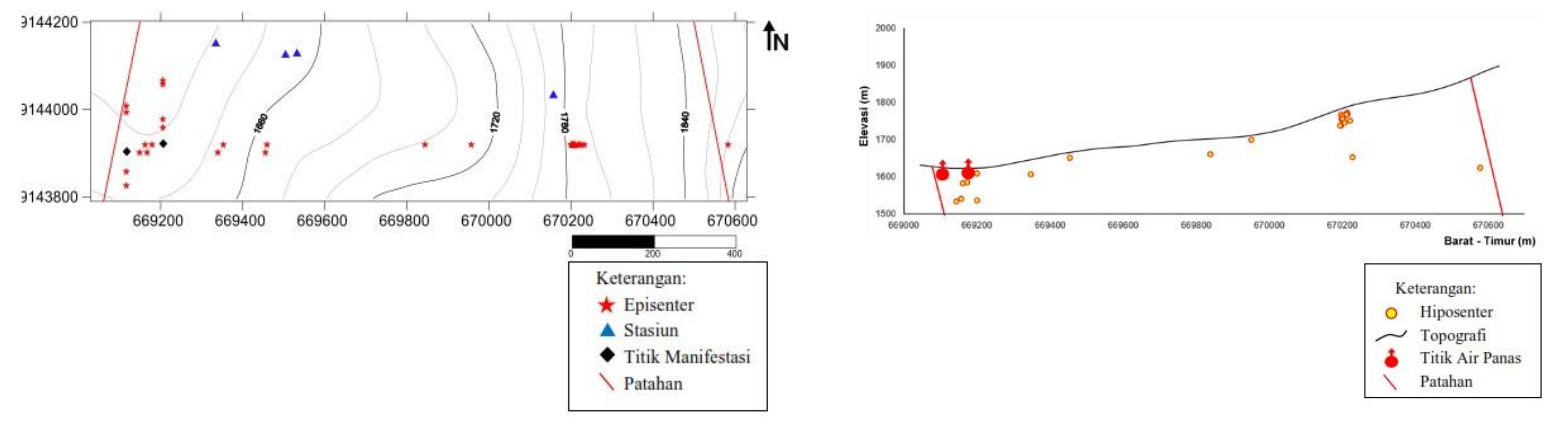

(a)
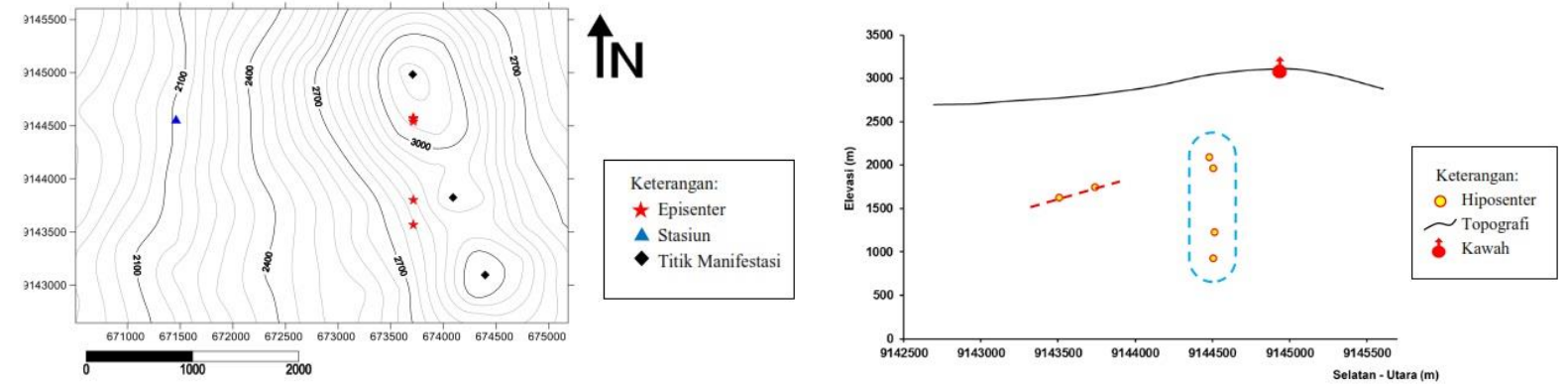

(b)

Gambar 3. Peta sebaran episenter (kiri) dan hiposenter (kanan) gempa mikro pada (a) sekitar titik air panas Cangar I dan Cangar 2, dan (b) sekitar kawah gunung Welirang. Penampang pada sebaran hiposenter di sekitar titik air panas merupakan 
penampang yang berarah Barat-Timur, sedangkan penampang pada sebaran hiposenter di sekitar kawah Welirang merupakan penampang berarah Selatan-Utara.

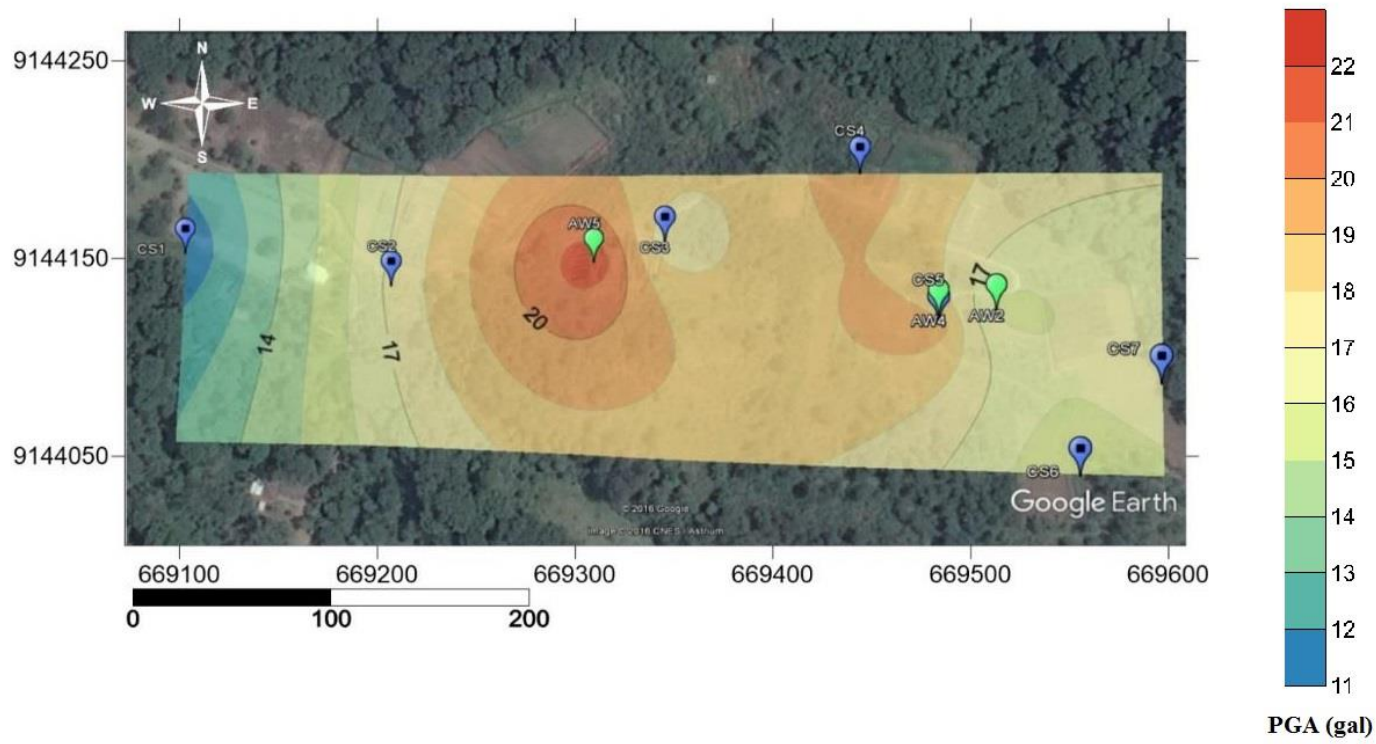

Gambar 4. Peta kontur persebaran nilai PGA di daerah Cangar.

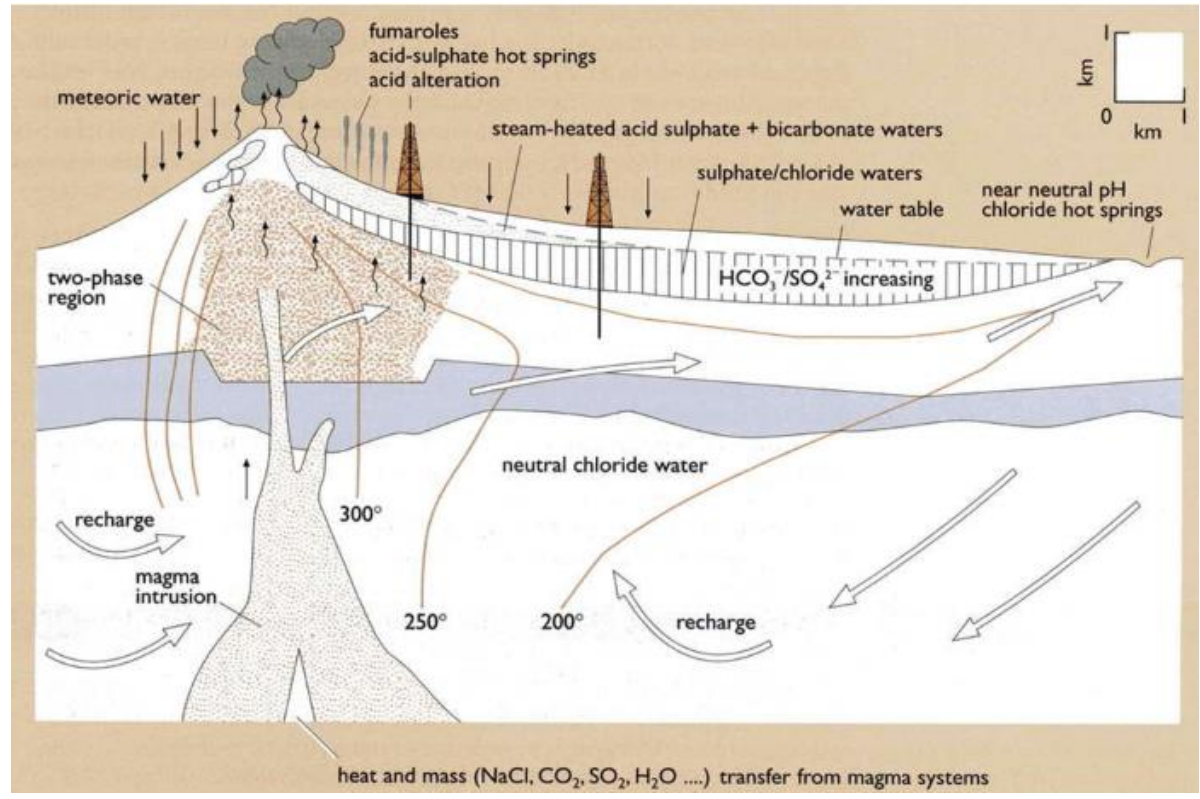

Gambar 5. Model konseptual daerah vulkano-geothermal yang diperlakukan kebijakan seimbang antara pemantauan bahaya gunung apinya dan pemanfaatan energi geothermalnya sehingga bisa bermanfaat secara seimbang.

Sebaran nilai PGA menurun di lokasi sekitar titik CS6, CS7, dan AW2. Lokasi ini masih masih berupa lahan luas dan relatif datar. Berdasarkan kondisi tersebut dengan nilai PGA yang diperoleh, lokasi tersebut cukup baik untuk dibangun gedung atau bangunan. Hal ini dapat dikaitkan pula dengan skala MMI yang telah ditampilkan pada Tabel 1, dimana dengan rentang nilai PGA yang telah disebutkan sebelumnya, lokasi Agrotechno Park Cangar cukup aman untuk dibangun gedung di sekitarnya karena memiliki tingkat resiko gempa bumi berada pada skala I - V. Gambar 5 menjelaskan model konseptual pemanfaatan dan pengembangan energi volcano geothermal yang seimbang. Model tersebut menggambarkan kondisi potensi yang ada pada volcano geothermal area 
baik potensi ancaman bahaya ataupun pemanfaatannya. Untuk itu diharapkan baik secara teknologi dan kebijakan harus dilakukan sebesar-besarnya untuk kemakmuran rakyat diberbagai sektor seperti, agroindustri, geowisata pendidikan, mitigasi bencana gunung api dan lain-lain.

\section{Kesimpulan dan Saran}

Dari penelitian yang telah dilakukan, didapatkan sebaran episenter gempa mikro di sekitar titik mata air panas Cangar dan di sekitar kawah gunung Welirang yang berasosiasi dengan patahan. Kedalaman gempa mikro di sekitar mata air panas cenderung dangkal yaitu 4-140 meter di bawah permukaan sedangkan untuk area di sekitar kawah memiliki kedalaman hiposenter 985-2152 meter di bawah kawah. Nilai PGA di Cangar berkisar 11.23 gal hingga 21.8 gal sehingga bisa direkomendasikan bahwa pada daerah Cangar merupakan daerah aman dari ancaman gempa bumi tektonik dan layak untuk pengembangan suatu Techno Park yang bisa menjadi wahana diseminasi pendidikan terkait dengan ancaman bahaya gunung api diimbangi dengan pendidikan tentang manfaat geothermal.

\section{Ucapan Terima Kasih}

Penelitian ini didukung oleh Hibah Penguatan Pusat Studi No. 730.2/UN10.C10/PN/2017, PTUPT tahun 2018, Program World Class University dari Universitas Brawijaya, semua anggota Pusat Studi Energi dan Sumber Daya Alam, Bravo Geothermal Research Center, Universitas Brawijaya.

\section{Daftar Rujukan}

[1] Badan Usaha Akademik Universitas Brawijaya (2016), Masterplan Agrotechno Park Cangar, Malang, https://www.youtube.com/watch?v=Nh0RaISQyaA (Diakses pada 28 Desember 2016).

[2] S. Maryanto (2017), Geo Techno Park Potential at Arjuno-Welirang Volcano Hosted Geothermal Area, Batu, East Java, Indonesia (Multi Geophysical Approach), AIP Conference Proceeding 1908, 030012-1.

[3] Tim Survey Terpadu PSDG (2010), Survey Terpadu Geologi dan Geokimia Daerah Panas Bumi Gunung Arjuno-Welirang Kabupaten Mojokerto, Malang dan Pasuruan Provinsi Jawa Timur, Bandung, Pusat Sumber Daya Geologi.

[4] M. N. Hadi, D. Kusnadi, dan Y. Rezky (2011), Penyelidikan Terpadu Geologi dan Geokimia Daerah Panas Bumi Arjuno-Welirang, Kabupaten Mojokerto dan Malang, Provinsi Jawa Timur, Prosiding Hasil Kegiatan Pusat Sumber Daya Geologi 2011, 405.

[5] Rahmawati, S. Maryanto, dan A. Susilo (2017), Identifikasi Sistem Panas Bumi Daerah Cangar, Jawa Timur Menggunakan Metode Magnetotelurik, Journal of Physical Science and Engineering 2,72 .

[6] N. Saptadji (2000), Sekilas Tentang Panas Bumi, Bandung, Institut Teknologi Bandung.

[7] D. Kurniawati, S. Maryanto, dan Wasis (2013), Penentuan Pusat Aktivitas Hidrothermal Daerah Cangar, Jawa Timur, Berdasarkan Analisis Pergerakan Partikel (Particle Motion), UB Student Journal of Physics 2013, 1.

[8] Y. Daud dan F. Fahmi (2015), Pemodelan Sistem Geothermal Arjuno-Welirang, Jawa Timur dengan Menggunakan Inversi Data Magnetotelurik 3-Dimensi, Depok, Universitas Indonesia.

[9] S. Inguaggiato, A. Mazzini, dan F. Vita (2015), The Geothermal System of the Arjuno-Welirang Volcano (East Java, Indonesia), USA, AGU Fall Meeting.

[10] Y. Daud, F. Fahmi, W. A. Nuqramadha, D. M. Heditama, S. A. Pratama, dan E. Suhanto (2015), 3-Dimensional Inversion of MT Data over the Arjuno-Welirang Volcanic Geothermal System, East Java (Indonesia).

[11] A. Wardana, J. O. Sullivan, dan M. O. Sulivan (2016), Natural State and Future Production Modelling of Arjuno-Welirang Geothermal Field, Indonesia, Proceedings 38th New Zealand Geothermal Workshop, Auckland, IGA.

[12] S. Inguaggiato, A. Mazzini, F. Vita, dan A. Sciarra (2017), The Arjuno-Welirang Volcanic Complex and the Connected Lusi System: Geochemical Evidences, Marine and Petroleum Geology 90, 67.

[13] U. Sumatarto (2018), Geothermal Energy Potential of Arjuno and Welirang Volcanoes Area, East Java, Indonesia, International Journal of Renewable Energy Research 8, 614.

[14] D. Edwiza dan S. Novita (2008), Pemetaan Percepatan Tanah Maksimum dan Intensitas Seismik Kota Padang Panjang Menggunakan Metode Kanai, Teknik A 2, 101. 
[15] Y. Febriani, I. Daruwati, dan R. G. Hatika (2013), Analisis Nilai Peak Ground Acceleration dan Indeks Kerentanan Seismik Berdasarkan Data Mikroseismik pada Daerah Rawan Gempa Bumi di Kota Bengkulu, Jurnal Pendidikan Edu Research 2, 85.

[16] B. Alessandrini, C. Marco, D. Martina, G. Marco, dan L. Valeria (1994), A Simple P-Wave Polarization Analysis: Its Application to Earthquake Location, Annali Di Geofisica 37, 883.

[17] N. B. Wibowo dan J. N. Sembri (2016), Analisis Peak Ground Acceleration (PGA) dan Intensitas Gempa Bumi Berdasarkan Data Gempa Bumi Terasa Tahun 1981-2014 di Kabupaten Bantul, Yogyakarta, Indonesian Journal of Applied Physics 6, 65.

[18] H. U. Mala, A. Susilo, dan Sunaryo (2015), Kajian Mikrotremor dan Geolistrik Resistivitas di Sekitar Jalan Arteri Primer Trans Timor untuk Mitigasi Bencana, Natural B 3, 24.

[19] S. Lunga, E. Minarto, dan S. Y. Y. Mantiri (2015), Pemetaan Tingkat Resiko Gempa Bumi di Sekitar Wilayah Kota Jayapura Berdasarkan Pengukuran Mikrotremor, Jurnal Fisika dan Aplikasinya 16, 55.

[20] K. Kanai dan T. Tanaka (1961), on Microtremor VIII, Bulletin of Earthquake Research Institute 39, 97.

[21] F. Rakhmanto, S. Maryanto, dan A. Susilo (2011), Tomografi Geolistrik Daerah Sumber Air Panas Cangar, Batu Kompleks Arjuno-Welirang, Natural B 1, 188. 